\title{
Genome wide association studies for body conformation traits in the Chinese Holstein cattle population
}

Xiaoping $\mathrm{Wu}^{1+}$, Ming Fang ${ }^{1,3+}$, Lin Liu², Sheng Wang ${ }^{1}$, Jianfeng Liu', Xiangdong Ding ${ }^{1}$, Shengli Zhang ${ }^{1}$, Qin Zhang ${ }^{1}$, Yuan Zhang ${ }^{1}$, Lv Qiao ${ }^{2}$, Mogens Sandø Lund ${ }^{4}$, Guosheng Su ${ }^{4}$ and Dongxiao Sun ${ }^{1 *}$

\begin{abstract}
Background: Genome-wide association study (GWAS) is a powerful tool for revealing the genetic basis of quantitative traits. However, studies using GWAS for conformation traits of cattle is comparatively less. This study aims to use GWAS to find the candidates genes for body conformation traits.

Results: The Illumina BovineSNP50 BeadChip was used to identify single nucleotide polymorphisms (SNPS) that are associated with body conformation traits. A least absolute shrinkage and selection operator (LASSO) was applied to detect multiple SNPs simultaneously for 29 body conformation traits with 1,314 Chinese Holstein cattle and 52,166 SNPs. Totally, 59 genome-wide significant SNPs associated with 26 conformation traits were detected by genome-wide association analysis; five SNPs were within previously reported QTL regions (Animal Quantitative Trait Loci (QTL) database) and 11 were very close to the reported SNPs. Twenty-two SNPs were located within annotated gene regions, while the remainder were $0.6-826 \mathrm{~kb}$ away from known genes. Some of the genes had clear biological functions related to conformation traits. By combining information about the previously reported QTL regions and the biological functions of the genes, we identified DARC, GAS1, MTPN, HTR2A, ZNF521, PDIA6, and TMEM130 as the most promising candidate genes for capacity and body depth, chest width, foot angle, angularity, rear leg side view, teat length, and animal size traits, respectively. We also found four SNPs that affected four pairs of traits, and the genetic correlation between each pair of traits ranged from 0.35 to 0.86 , suggesting that these SNPs may have a pleiotropic effect on each pair of traits.
\end{abstract}

Conclusions: A total of 59 significant SNPs associated with 26 conformation traits were identified in the Chinese Holstein population. Six promising candidate genes were suggested, and four SNPs showed genetic correlation for four pairs of traits.

Keywords: Dairy cattle, GWAS, Body conformation traits, SNP, Holstein, QTL

\section{Background}

Since the 1990s, body conformation traits have been used in dairy cattle breeding programs in many countries. Although these traits themselves are not of economic interest to breeders, they are closely related to many economic traits, such as the health, productivity,

\footnotetext{
* Correspondence: sundx@cau.edu.cn

${ }^{\dagger}$ Equal contributors

'Key Laboratory of Animal Genetics and Breeding of Ministry of Agriculture, National Engineering Laboratory for Animal Breeding, College of Animal Science and Technology, China Agricultural University, 2 Yuanmingyuan West Road, Beijing 100193, China

Full list of author information is available at the end of the article
}

and lifetime of cattle. Vollema et al. [1] reported that some conformation traits such as body depth, rump angle, rump width, and udder depth were useful predictors of lifetime and longevity in Dutch dairy bull populations because of the genetic correlation between them. Lund et al. [2] showed that genetic correlations between health and type traits were generally moderate $(-0.32$ to 0.37 ) and that selection for improved udder conformation reduced the somatic cell count and the occurrence of clinical mastitis. Short and Lawlor [3] found that genetic correlations between linear type traits and first lactation yield ranged from 0.48 to 0.54 . Pozveh et al.

\section{Biomed Central}


reported that body depth had genetic correlations with many other economic traits, such as the days from calving to first-insemination (0.79), calving interval (0.35), and gestation length (0.34). Stature was also genetically correlated with gestation length (0.49) [4]. Therefore, quantitative trait loci (QTLs) associated with body conformation traits are economically as important as other economic traits.

With the availability of a high-density chip with single nucleotide polymorphisms (SNPs) for bovine, genomewide association study (GWAS) has become a useful tool for fine-scale QTL mapping. This approach has been widely applied to causative mutation detection in human [5,6], mouse [7] and cattle [8,9]. By using very large numbers of SNPs researcher can easily detect statistical associations between SNPs and phenotypes, and thus biologically meaningful candidate genes close to the significant SNPs are identified for further study. This procedure greatly narrows down the regions of the genome that contain the causative mutations. The associations can provide direct and necessary evidence for the function of a gene.

Recently, many GWASs have been focused on the economic traits in dairy cattle, including production traits $[8,10-15]$, fertility traits $[8,16-18]$, disease resistance $[9,19,20]$, and somatic cell score [13], and many statistically significant SNPs and biologically meaningful genes have been reported. However, comparatively few studies about body conformation traits have been published [8,21]. Linkage analysis has been used by some researchers to detect QTLs associated with conformation traits [22-24]. Schrooten et al. [22] used microsatellite markers in a whole genome scan for QTLs affecting 18 conformation traits. Ashwell et al. [23] detected QTLs affecting 22 conformation traits, including body, udder, feet, legs, and dairy conformation, and found 41 chromosome-wise significant QTLs. Cole et al. [8] used a single-locus model to analyze 18 body conformation traits, which included six trait groups, body size, body shape, udder, teats, teats, feet and legs, and final score and reported the top 100 effects for each trait. Their results showed that traits within a phenotype group had a tendency of sharing common SNP effects.

In this research, we performed a genome wide association study for 29 conformation traits in a Chinese Holstein population, which included 1314 Chinese Holstein cattle and 52,166 SNPs. A LASSO-like multiple-SNP method was applied to identify multiple SNPs simultaneously. The genes closest to the significant SNPs (within a $1 \mathrm{Mb}$ region) were annotated.

\section{Methods}

Blood samples were collected from Chinese Holstein cattle when the regular quarantine inspection of the farms was conducted. The procedure for collecting the blood samples was carried out in strict accordance with the protocol approved by the Animal Welfare Committee of China Agricultural University (Permit Number: DK996).

\section{Phenotype and genotype data}

The Chinese Holstein population in this study comprised 1314 Chinese Holstein cows, the daughters of 22 sires. All the cows were from 22 dairy cattle farms in the Beijing Dairy Cattle Center and the Beijing Sanyuan Lvhe Dairy Farming Center where regular and standard performance tests, including measurement of conformation traits, have been carried out since 1999 as part of the Dairy Herd Improvement (DHI) system. According to the linear classification system defined by Dairy Data Center of China, Dairy Association of China (DAC) [25], 21 linear type traits were scored from 1 to 9 , and eight composite traits were measured using an index with values and scored from 0 to 100 . The 21 traits were animal size, stature, height at front end, chest width, body depth, loin strength, rump width, rump angle, bone quality, foot angle, rear legs side view, udder depth, udder texture, median suspensory, fore udder attachment, front teat placement, teat length, rear attachment height, rear attachment width, rear teat placement, and angularity. The eight function score traits were conformation (final score), dairy character, capacity, rump, feet and legs, fore udder, rear udder, and mammary system. Calculation of the scores for the eight composite traits was based on linear score, weights, and defective traits. The phenotypic values of the 21 conformation traits in the first lactation of the cows were measured by the Beijing Dairy Cattle Center [26] and then the genetic parameters of all 29 traits were estimated [27]. The estimated breeding values (EBVs) were calculated with a multiple-trait random regression test-day model using the RunGE software purchased from Canadian Dairy Network [28] by the Dairy Data Center of China. The descriptive statistics of the EBVs for the 29 traits in the 1314 individuals are listed in Table 1 . The genetic correlations between each pair of traits were also calculated (see Additional file 1 for details). To conveniently generalize the results, the correlation coefficients (a total of $29 * 28 / 2=406$ pair-wise values) were classified into five levels, -1 to $-0.66,-0.66$ to $-0.33,-0.33$ to $0.33,0.33$ to 0.66 , and 0.66 to 1 , and were defined as high-level negative correlation, medium-level negative correlation, weak-level correlation, medium-level positive correlation, high-level positive correlation, respectively (Table 2). The results show that 15 of 406 pairs of traits (7.2\%) have highlevel positive correlations, while most of the pairs have weak correlations $(75.2 \%)$.

The animals were genotyped using the Illumina BovineSNP50 BeadChip (Illumina Inc., San Diego, CA, USA). Some individuals were genotyped using the Illumina $54 \mathrm{~K}$ 
Table 1 Statistics of the estimated breeding values for the 29 conformation traits used in the GWAS

\begin{tabular}{|c|c|c|c|c|c|c|c|}
\hline Traits & $\mathrm{N}$ & Mean & Variance & SD & Min & Max & Heritability \\
\hline Conformation (final score) & 1314 & -1.58 & 9.73 & 3.12 & -14 & 8 & 0.21 \\
\hline Capacity & 1314 & -1.92 & 14.61 & 3.82 & -14 & 10 & 0.29 \\
\hline Stature & 1314 & -1.74 & 21.88 & 4.68 & -25 & 13 & 0.37 \\
\hline Height at front end & 1314 & -0.96 & 8.42 & 2.90 & -11 & 10 & 0.14 \\
\hline Animal size & 1314 & -1.50 & 15.27 & 3.91 & -17 & 12 & 0.37 \\
\hline Chest width & 1314 & -2.59 & 14.30 & 3.78 & -14 & 7 & 0.09 \\
\hline Body depth & 1314 & -0.84 & 13.76 & 3.71 & -15 & 8 & 0.19 \\
\hline Rump & 1314 & -1.24 & 11.68 & 3.42 & -12 & 11 & 0.07 \\
\hline Rump angle & 1314 & -0.52 & 18.87 & 4.34 & -16 & 14 & 0.26 \\
\hline Rump width & 1314 & -0.87 & 24.09 & 4.91 & -18 & 21 & 0.07 \\
\hline Loin strength & 1314 & -1.41 & 17.42 & 4.17 & -19 & 11 & 0.17 \\
\hline Feet and legs & 1314 & -1.48 & 7.17 & 2.68 & -11 & 7 & 0.09 \\
\hline Foot angle & 1314 & -1.03 & 12.11 & 3.48 & -16 & 11 & 0.13 \\
\hline Bone quality & 1314 & -0.11 & 13.05 & 3.61 & -14 & 10 & 0.10 \\
\hline Rear legs side view & 1314 & 0.01 & 14.63 & 3.82 & -17 & 13 & 0.24 \\
\hline Mammary system & 1314 & -0.81 & 13.06 & 3.61 & -16 & 10 & 0.19 \\
\hline Udder depth & 1314 & -1.60 & 9.59 & 3.10 & -15 & 8 & 0.22 \\
\hline Udder texture & 1314 & -1.17 & 8.39 & 2.90 & -12 & 7 & 0.08 \\
\hline Median suspensory & 1314 & -0.44 & 15.10 & 3.89 & -13 & 13 & 0.17 \\
\hline Fore udder & 1314 & -0.59 & 15.19 & 3.90 & -16 & 12 & 0.17 \\
\hline Fore attachment & 1314 & -0.20 & 19.12 & 4.37 & -15 & 11 & 0.27 \\
\hline Fore teat placement & 1314 & -0.64 & 13.37 & 3.66 & -13 & 12 & 0.10 \\
\hline Teat length & 1314 & 0.22 & 12.60 & 3.55 & -16 & 11 & 0.18 \\
\hline Rear udder & 1314 & -0.70 & 13.16 & 3.63 & -16 & 11 & 0.21 \\
\hline Rear attachment height & 1314 & -0.30 & 8.95 & 2.99 & -11 & 8 & 0.15 \\
\hline Rear attachment width & 1314 & -1.23 & 11.34 & 3.37 & -13 & 10 & 0.19 \\
\hline Rear teat placement & 1314 & -1.63 & 9.97 & 3.16 & -12 & 9 & 0.11 \\
\hline Dairy character & 1314 & -1.50 & 16.40 & 4.05 & -19 & 11 & 0.34 \\
\hline Angularity & 1314 & -1.39 & 12.22 & 3.50 & -18 & 10 & 0.18 \\
\hline
\end{tabular}

Note: N, SD, Min and Max means observations, standard deviation, minimum and maximum, respectively.

chip version1 containing 54,001 SNPs, while others were genotyped using the $54 \mathrm{~K}$ chip version 2 containing 54,609 SNPs. Genotype imputation was conducted for all the genotyped individuals using the Beagle software, version 3.1.0 [29,30]. After imputation, there were 56,270 SNPs in the marker data. SNPs were excluded from the analysis if the minor allele frequency (MAF) was less than 1\%, the call rate was less than $90 \%$, or the genotype frequency deviated from Hardy-Weinberg Equilibrium (HWE) with a $P$-value lower than $10^{-6}$. After quality control, 1314 individuals with 52,166 SNPs remained for the GWAS. After editing, the average distance between adjacent SNPs on the genome was $59.59 \mathrm{~kb}$, and the median distance was $49.00 \mathrm{~kb}$. Finally, the association analysis was conducted between each trait and 52,166 SNPs on 29 autosomes and $\mathrm{X}$ chromosome in the bovine genome.

\section{Statistical analyses}

Statistical tests of SNP effects were conducted using the expectation maximization algorithm based on an improved

Table 2 Summary of the frequencies of pair-wise genetic correlations among 29 conformation traits

\begin{tabular}{|c|c|c|c|c|c|c|}
\hline Range & $(-1$ to -0.66$)$ & $(-0.66$ to -0.33$)$ & $(-0.33$ to 0.33$)$ & $(0.33$ to 0.66$)$ & $(0.66$ to 1$)$ & Total \\
\hline Number & 0 & 3 & 306 & 82 & 15 & 406 \\
\hline Frequency & 0 & 0.007 & 0.752 & 0.201 & 0.072 & 1 \\
\hline
\end{tabular}


least absolute shrinkage and selection operator (LASSO) [31] method. This method simultaneously estimates multiple SNP effects and shrinks the effects of zero-effect SNPs towards zero, and thus avoids complex model selection (Fang et al. 2013, unpublished).

The GWAS was carried out in two steps. First, single trait mixed model analysis (SMMA) was applied to estimate the effect of each SNP. Then, the first 500 markers (why 500 markers were used is explained in the Discussion section) with the lowest $P$-values were selected for the multiple-SNP analysis.

The linear model that was used to estimate the effect of the $j$ th SNP can be expressed as:

$$
\mathbf{y}=\mathbf{1} \mu+\mathbf{x}_{\mathbf{j}} \beta_{\mathrm{j}}+\mathbf{Z g}+\mathbf{e}
$$

where $\mathbf{y}$ is the vector of EBVs, $\mathbf{1}$ is the vector with its elements of $1, \boldsymbol{\mu}$ is the population mean; $\mathbf{x}_{\mathbf{j}}$ is the vector of the genotype of the $j$ th SNP marker, which is assigned to $-1,0$, and 1 for genotypes $\mathrm{AA}, \mathrm{AB}$ and $\mathrm{BB}$, respectively, and $\boldsymbol{\beta}_{j}$ is the SNP effect; $\mathbf{g}$ is the vector of polygenic effects, and $\mathbf{Z}$ is the design matrix related to the polygenic effect; $\mathbf{e}$ is the vector of random residuals. It is assumed that $\mathbf{g}^{\sim} N\left(\mathbf{0}, \mathbf{A} \sigma_{g}^{2}\right)$ and $\mathbf{e}^{\sim} N\left(\mathbf{0}, \mathbf{I} \sigma_{e}^{2}\right)$, where $\mathbf{A}$ is the additive genetic relationship matrix based on pedigree, $\sigma_{g}^{2}$ is the variance of polygenic effect, I is an identity matrix, and $\sigma_{e}^{2}$ is the residual variance. When a single-SNP mixed model was applied, the computational time was extremely large because of the iterative calculation of variance components (Best Linear Unbiased Prediction). Therefore, we first approximately calculated the variance components without considering a QTL effect and then imposed the estimates of variance components on the mixed model equation, which does not need an iterative calculation and thus reduces computational time.

For the SMMA analysis, the significance of the SNP effect was tested using a t-test with null hypothesis of $\beta=$ 0 , and the Bonferroni correction was applied to control the false positives. So, the threshold for significant associations was $-\log _{10}(0.05 / N)$, where $N$ is the number of SNP loci tested in the analysis.

The model to estimated effects of the SNPs selected from the first step can be expressed as:

$$
\mathbf{y}=\mathbf{1} \mu+\mathbf{X} \boldsymbol{\beta}+\mathbf{Z g}+\mathbf{e}
$$

where $\mathbf{X}$ is the matrix of genotype covariables of the 500 SNPs, and $\boldsymbol{\beta}$ is the vector of SNP effects. An expectation-maximization algorithm was adopted to estimate the model parameters. The method assigned an improved LASSO prior $\pi\left(\beta_{j}\right)=\frac{\lambda_{j}}{2} e^{-\lambda_{j}\left|\beta_{j}\right|}$ to SNP effect $\beta_{j}[32]$, where the hyper-parameter $\lambda_{j}^{2} / 2$ is assigned a conjugate gamma prior with gamma $(a, b)$, where $a$ and $b$ are very small values, and both $a$ and $b$ are taken as $10^{-6}$. The prior of the residual polygenic effect follows the normal distribution $g \mid \sigma_{g}^{2 \sim} N\left(0, \mathbf{A} \sigma_{g}^{2}\right)$, where $\sigma_{g}^{2}$ is the residual polygenic variance and $\mathbf{A}$ is the additive genetic relationship matrix. The expectation-maximization algorithm was applied to estimate SNP effects $\boldsymbol{\beta}_{j}$ by finding the maximum posterior mode, which treats the polygenic effect $(g)$ as a missing variable (see Additional file 2 for details).

The threshold value for declaring the significance of the SNP was determined from the empirical distribution of the heritability of SNP $j$ (the SNP with the largest heritability across the genome for each permutation), $h_{j}^{2}=\sigma_{j}^{2}$ / $\left(\sum_{j=1}^{p} \sigma_{j}^{2}+\sigma_{g}^{2}+\sigma_{e}^{2}\right)$, derived from 1,000 permutations, where $\sigma_{j}^{2}=2 p_{j}\left(1-p_{j}\right) \beta_{j}^{2}$ is the variance of the $j$ th SNP, and $p_{j}$ is the allele frequency of the SNP. Here, heritability was used to measure the strength of each SNP, which is fairer than using the SNP effect, because the allele frequency of each SNP is different.

\section{Identification of SNP locations and gene annotation}

The locations of significant SNPs were reported based on the UMD3.1 assembly of bovine genome sequence (assembled by the Center for Bioinformatics and Computational Biology (CBCB) at University of Maryland). The genes that were closest to the significant SNPs (within $1 \mathrm{Mb}$ ) were determined by the National Animal Genome Research Program [33] and the National Center for Biotechnology Information [34]).

\section{Results}

A total of 59 genome-wise significant SNPs associated with 26 out of the 29 conformation traits were found by our improved LASSO method. Twenty-two of the SNPs were located within 22 known genes regions. We identified the 26 conformation traits into six trait group, and investigated the significant SNPs associated with each of these traits as described below.

\section{Dairy character traits}

Three and two SNPs were associated with dairy character and angularity respectively (Table 3 ). Among them, dairy character and angularity shared one common SNP, which was located $45 \mathrm{~kb}$ away from SLC25A24 on Bos taurus chromosome 3 (BTA3). For dairy character, one SNP was located within SCEL on BTA12 and the other SNP was $14 \mathrm{~kb}$ away from SPATA17. For angularity, the other SNP was $261 \mathrm{~kb}$ away from HTR2A.

\section{Capacity traits}

For body depth, height at front end, and animal size, each trait was associated with one significant SNP; for 
Table 3 Genome-wide significant SNPs for final conformation score and dairy character traits

\begin{tabular}{llllllll}
\hline Trait & SNP name & Chr. & Position (bp) & Nearest gene & Distance (bp) & Heritability & Threshold \\
\hline Conformation (final score) & ARS-BFGL-NGS-109711 & 5 & 110149999 & ANKRD54 & within & 0.00980 & 0.00942 \\
Dairy character & ARS-BFGL-NGS-14022 & 3 & 35255950 & SLC25A24 & 45,501 & 0.01490 & 0.00929 \\
& BTB-01238380 & 12 & 53100776 & SCEL & within & 0.00936 & 0.00929 \\
& ARS-BFGL-NGS-55380 & 16 & 21821449 & SPATA17 & 14,623 & 0.00990 & 0.00929 \\
Angularity & ARS-BFGL-NGS-14022 & 3 & 35255950 & SLC25A24 & 45,501 & 0.01100 & 0.00969 \\
& ARS-BFGL-NGS-113826 & 12 & 17150394 & HTR2A & 261,113 & 0.01320 & 0.00969 \\
\hline
\end{tabular}

Note: Heritability and threshold were obtained using the LASSO method. Nearest gene are symbols of gene full name in the NCBI database (http://www.ncbi.nlm.nih.gov/).

stature and loin strength, each trait was associated with two SNPs; and for chest width and capacity, each trait was associated with five SNPs (Table 4). Among them, the SNP on BTA3 was $7 \mathrm{~kb}$ away from DARC and was associated with both body depth and capacity; and the SNP on BTA25 was $9 \mathrm{~kb}$ away from TMEM130, and was associated with both body depth and animal size. The SNPs at $39 \mathrm{Mb}$ on BTA9, $115 \mathrm{Mb}$ on BTA6, $35 \mathrm{Mb}$ on BTA15, $53 \mathrm{Mb}$ on BTA12, and $10 \mathrm{Mb}$ on BTA 18 were associated with capacity, stature, loin strength, height at front end, and chest width, respectively, and all of them were located in regions of the chromosomes that contained known genes. The remaining SNPs were at distances of $3 \mathrm{~kb}$ to $19 \mathrm{~kb}$ from the nearest known genes.

\section{Rump traits}

Eleven significant SNPs on different chromosomes were associated with rump traits (Table 5). Two and three of these SNPs were associated with rump and rump angle, respectively, and all of them were located within regions of the chromosomes that contained known genes. The remaining significant SNPs were at distances of $48 \mathrm{~kb}$ to $826 \mathrm{~kb}$ from the nearest known genes.

\section{Feet and legs traits}

Twelve significant SNPs were detected for feet and legs traits (Table 6). Three of these SNPs, for feet and legs, foot angle, and rear leg side view, were located within DHX35 on BTA13, PLEKHB2 on BTA2, and DOCK10 on BTA2, respectively. Two SNPs on BTA3 and BTA27 for feet and legs, two SNPs on BTA1 and BTA15 for bone quality, three SNPs on BTA3, BTA4, and BTA22 for foot angle, two SNPs on BTA14 and BTA 24 for rear leg side view were located at distances of $3 \mathrm{~kb}$ to $420 \mathrm{~kb}$ from the nearest known genes.

Table 4 Genome-wide significant SNPs for capacity and the component traits

\begin{tabular}{llllllll}
\hline Trait & SNP name & Chr. & Position (bp) & Nearest gene & Distance (bp) & Heritability & Threshold \\
\hline Capacity & Hapmap40339-BTA-117016 & 3 & 10640386 & DARC & 7,094 & 0.01100 & 0.00894 \\
& ARS-BFGL-NGS-114456 & 7 & 30964539 & LOC789456 & 97,615 & 0.01100 & 0.00894 \\
& ARS-BFGL-NGS-44162 & 9 & 39626344 & LOC539486 & within & 0.01160 & 0.00894 \\
& ARS-BFGL-NGS-26589 & 18 & 4852600 & NUDT7 & 137,863 & 0.01080 & 0.00894 \\
& ARS-BFGL-NGS-115067 & 25 & 37927752 & TMEM130 & 8,967 & 0.01280 & 0.00894 \\
Stature & Hapmap60794-rs29022851 & 6 & 115008971 & CPEB2 & within & 0.01110 & 0.00953 \\
& BTA-72885-no-rs & 29 & 19560064 & LOC782090 & 81,135 & 0.01370 & 0.00953 \\
Body depth & Hapmap40339-BTA-117016 & 3 & 10640386 & DARC & 7,094 & 0.00884 & 0.00872 \\
Loin strength & ARS-BFGL-NGS-70552 & 15 & 35177124 & SERGEF & within & 0.01340 & 0.00895 \\
& BTB-00938945 & 26 & 32943986 & GPAM & 19,414 & 0.00908 & 0.00895 \\
Height at front end & BTB-01238380 & 12 & 53100776 & SCEL & within & 0.00875 \\
Animal size & ARS-BFGL-NGS-115067 & 25 & 37927752 & TMEM130 & 8,967 & 0.00811 \\
Chest width & BTA-110160-no-rs & 8 & 81389800 & GAS1 & 121,119 & 0.01130 & 0.00953 \\
& ARS-BFGL-NGS-115466 & 18 & 10002426 & CDH13 & within & 0.01410 \\
& BTA-45515-no-rs & 19 & 43170256 & PTRF & 8,091 & 0.00969 \\
& BTB-00922140 & 4 & 82550244 & POU6F2 & 54,944 & 0.00969 \\
& ARS-BFGL-NGS-57462 & 25 & 8086468 & LOC538487 & 131,274 & 0.01070
\end{tabular}

Note: Heritability and threshold were obtained using the LASSO method. Nearest gene are symbols of gene full name in the NCBI database (http://www.ncbi.nlm.nih.gov/). 
Table 5 Genome-wide significant SNPs for rump and the component traits

\begin{tabular}{|c|c|c|c|c|c|c|c|}
\hline Trait & SNP name & Chr. & Position (bp) & Nearest gene & Distance (bp) & Heritability/- $\log _{10}(P)^{b}$ & Threshold \\
\hline \multirow[t]{3}{*}{ Rump } & BTB-01660659 & 1 & 145986598 & KRTAP10-12 & 688 & 0.01280 & 0.00916 \\
\hline & ARS-BFGL-NGS-12856 & 4 & 8155616 & CDK14 & within & 0.01100 & 0.00916 \\
\hline & BTB-00323505 & 7 & 82338362 & ODZ2 & within & 0.00966 & 0.00916 \\
\hline \multirow[t]{10}{*}{ Rump width } & BTB-00168895 & 4 & 20788689 & LOC781728 & 166,306 & 0.01260 & 0.00917 \\
\hline & Hapmap40061-BTA-28737 & 9 & 1775187 & LOC616304 & 826,933 & 0.00924 & 0.00917 \\
\hline & BTB-02035532 & 7 & 58436123 & LOC100138639 & 348,605 & $6.07^{b}$ & $6.02^{c}$ \\
\hline & ARS-BFGL-NGS-14128 & 10 & 36665562 & ACYP2 & within & $7.21^{\mathrm{b}}$ & $6.02^{c}$ \\
\hline & ARS-BFGL-NGS-86147 & 10 & 49856100 & ACYP2 & 44,441 & $6.89^{b}$ & $6.02^{c}$ \\
\hline & ARS-BFGL-NGS-53281 ${ }^{\mathrm{a}}$ & 15 & 66603229 & SLCIAZ & within & $8.35^{b}$ & $6.02^{c}$ \\
\hline & BTB-00611649 & 15 & 67429625 & LDLRAD3 & within & $6.05^{b}$ & $6.02^{c}$ \\
\hline & ARS-BFGL-NGS-97658 & 15 & 68069900 & C15H11orf74 & 158,748 & $7.27^{b}$ & $6.02^{c}$ \\
\hline & BTA-30189-no-rs ${ }^{a}$ & $x$ & 60101130 & MAGED2 & 42,513 & $6.34^{b}$ & $6.02^{c}$ \\
\hline & ARS-BFGL-NGS-80859 & $x$ & 61237718 & NXF3 & 338,723 & $7.01^{b}$ & $6.02^{c}$ \\
\hline \multirow[t]{6}{*}{ Rump angle } & BTA-94299-no-rs & 5 & 93940507 & MGST1 & within & 0.01500 & 0.00906 \\
\hline & Hapmap48553-BTA-10000 & 7 & 59019641 & LOC788619 & 36,977 & 0.01610 & 0.00906 \\
\hline & BTB-01219012 & 7 & 65799159 & LOC100296765 & 48,625 & 0.01020 & 0.00906 \\
\hline & ARS-BFGL-NGS-31810 & 11 & 105631144 & LOC536255 & within & 0.00960 & 0.00906 \\
\hline & ARS-BFGL-NGS-54462 & 25 & 13405791 & MIR365 & 61,471 & 0.01190 & 0.00906 \\
\hline & ARS-BFGL-NGS-102900 & 27 & 4720968 & AGPAT5 & within & 0.01300 & 0.00906 \\
\hline
\end{tabular}

Note: Heritability and threshold were obtained using the LASSO method; - $\log _{10}(P)$ was calculated using SMMA. ${ }^{\mathrm{a} S N P}$ detected by SMMA only; ${ }^{\mathrm{b}}$-log ${ }_{10}(P)$ obtained

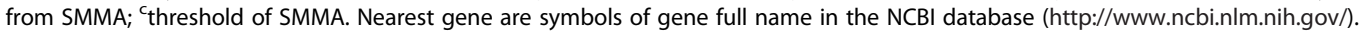

\section{Mammary system traits}

A total of 17 significant SNPs were detected for mammary system traits (Table 7). Of these SNPs, one associated with rear udder was located within LOC100337279 on BTA14; two associated with udder texture were within LOC100295233 and DRG1 on BTA3 and BTA7, respectively; two associated with median suspensory fell were within LRP2 and MACROD2 on BTA2 and BTA13, respectively; one associated with fore teat placement was located within SLC39A11 on BTA19; and one associated

Table 6 Genome-wide significant SNPs for feet and legs and the component traits

\begin{tabular}{|c|c|c|c|c|c|c|c|}
\hline Trait & SNP name & Chr. & Position (bp) & Nearest gene & Distance (bp) & Heritability/- $\log _{10}(P)^{\mathrm{b}}$ & Threshold \\
\hline \multirow[t]{4}{*}{ Feet and legs } & Hapmap48847-BTA-67772 & 3 & 48281407 & RWDD3 & 116,751 & 0.01530 & 0.00948 \\
\hline & ARS-BFGL-NGS-76581 & 27 & 39783292 & OXSM & 78,430 & 0.01290 & 0.00948 \\
\hline & Hapmap53251-rs29027216 & 13 & 68437003 & DHX35 & within & 0.01050 & 0.00948 \\
\hline & Hapmap49594-BTA-39447ª & 1 & 20165566 & LOC101905904 & within & $6.54^{b}$ & $6.02^{c}$ \\
\hline \multirow[t]{2}{*}{ Bone quality } & BTA-87372-no-rs & 1 & 30724028 & LOC100337296 & 420,082 & 0.00967 & 0.00949 \\
\hline & BTA-117758-no-rs & 15 & 72591774 & C8H9orf30 & 112,905 & 0.00964 & 0.00949 \\
\hline \multirow[t]{4}{*}{ Foot angle } & ARS-BFGL-NGS-18261 & 2 & 1896078 & PLEKHB2 & within & 0.01010 & 0.00929 \\
\hline & ARS-BFGL-NGS-73625 & 3 & 14218748 & NES & 3,146 & 0.01060 & 0.00929 \\
\hline & Hapmap48448-BTA-71823 & 4 & 100663967 & MTPN & 37,399 & 0.00943 & 0.00929 \\
\hline & ARS-BFGL-NGS-113718 & 22 & 2655659 & $C M C 1$ & 29,461 & 0.01120 & 0.00929 \\
\hline \multirow[t]{4}{*}{ Rear leg side view } & ARS-BFGL-NGS-97763 & 2 & 113852386 & DOCK10 & within & 0.01020 & 0.00942 \\
\hline & Hapmap29973-BTA-129162 & 14 & 46264806 & PAG1 & 71,476 & 0.00978 & 0.00942 \\
\hline & UA-IFASA-4800 & 24 & 31524371 & ZNF521 & 151,162 & 0.01230 & 0.00942 \\
\hline & Hapmap52451-rs29021142ª & 1 & 138784934 & KCNH8 & 106,181 & $6.25^{b}$ & $6.02^{c}$ \\
\hline
\end{tabular}

Note: Heritability and threshold were obtained using the LASSO method; - $\log _{10}(P)$ was calculated using SMMA. ${ }^{a}$ SNP detected by SMMA only; ${ }^{\text {b-log }}$ ( $(P)$ obtained from SMMA; ${ }^{c}$ threshold of SMMA. Nearest gene are symbols of gene full name in the NCBI database (http://www.ncbi.nlm.nih.gov/). 
Table 7 Genome-wide significant SNPs for mammary system traits

\begin{tabular}{|c|c|c|c|c|c|c|c|}
\hline Trait & SNP name & Chr. & Position (bp) & Nearest gene & Distance (bp) & Heritability/- $\log _{10}(P)^{b}$ & Threshold \\
\hline \multirow[t]{2}{*}{ Rear udder } & ARS-BFGL-NGS-111920 & 14 & 44029634 & LOC100337279 & within & 0.01330 & 0.00891 \\
\hline & Hapmap50827-BTA-94026 & 24 & 2166631 & LOC100336384 & 39,890 & 0.01130 & 0.00891 \\
\hline \multirow[t]{3}{*}{ Udder texture } & ARS-BFGL-NGS-104839 & 3 & 88712390 & LOC100295233 & within & 0.00873 & 0.00872 \\
\hline & BTA-41935-no-rs & 17 & 72284836 & $D R G 1$ & within & 0.01670 & 0.00872 \\
\hline & BTB-01236227 & 20 & 15824409 & HTR1A & 264,560 & 0.00941 & 0.00872 \\
\hline \multirow[t]{5}{*}{ Median suspensory } & BTB-00089278 & 2 & 26942975 & $\angle R P 2$ & within & 0.01080 & 0.00874 \\
\hline & BTB-01007411 & 4 & 37145925 & SEMA3E & 960 & 0.00995 & 0.00874 \\
\hline & ARS-BFGL-NGS-35982 & 5 & 5693439 & NAP1L1 & 81,318 & 0.00941 & 0.00874 \\
\hline & ARS-BFGL-NGS-29118 & 13 & 8497369 & MACROD2 & within & 0.01490 & 0.00874 \\
\hline & ARS-BFGL-NGS-52278 & 12 & 89182471 & RAB20 & within & $7.85^{\mathrm{b}}$ & $6.02^{c}$ \\
\hline Fore attachment & ARS-BFGL-NGS-114960 & 29 & 36024434 & NTM & 448,744 & 0.01050 & 0.00965 \\
\hline Fore teat Placement & ARS-BFGL-NGS-113245 & 19 & 59068269 & SLC39A11 & within & 0.01290 & 0.00892 \\
\hline Teat length & BTB-01255458 & 10 & 99270875 & PDIA6 & 80,295 & 0.01030 & 0.00911 \\
\hline \multirow[t]{2}{*}{ Rear attach height } & ARS-BFGL-NGS-20052 & 2 & 107616903 & CDK5R2 & 3,609 & 0.00988 & 0.00904 \\
\hline & Hapmap43038-BTA-76203 & 6 & 50316616 & LOC100298058 & 12,846 & 0.00997 & 0.00904 \\
\hline Rear attach Width & BTB-01478363 & 20 & 17370437 & $B A G 1$ & 210,690 & 0.00938 & 0.00924 \\
\hline \multirow[t]{2}{*}{ Rear teat Placement } & ARS-BFGL-NGS-31730 & 11 & 44265651 & SH3RF3 & within & 0.00927 & 0.00864 \\
\hline & BTB-01230622 & 15 & 62600934 & DCDC5 & 61,622 & 0.01200 & 0.00864 \\
\hline
\end{tabular}

Note: Heritability and threshold were obtained using the LASSO method; - $\log _{10}(P)$ was calculated using SMMA. ${ }^{a}$ SNP detected by SMMA only; ${ }^{\mathrm{b}}$-log ${ }_{10}(P)$ obtained from SMMA; ${ }^{c}$ threshold of SMMA. Nearest gene are symbols of gene full name in the NCBI database (http://www.ncbi.nlm.nih.gov/).

with rear teat placement was located within SH3RF3 on BTA11. The other 10 SNPs were located at distances of $960 \mathrm{bp}$ to $448 \mathrm{~kb}$ from the nearest known genes.

\section{Final conformation score}

A SNPs on BTA5 (Table 3) was found to be associated with final conformation score, and this SNP was harbored within ANKRD54, which encodes an ankyrin repeat domain-containing protein.
The estimated heritability for 29 conformation traits obtained using improved LASSO was plotted and the figures are available in Additional file 3.

The results obtained using SMMA are also listed in Tables 6, 7 and 8. Only 11 significant SNPs were detected and eight of them were significantly associated with rump width. The other three SNPs were associated with rear legs side view, median suspensory, and feet and legs.

When we compared our results with those of Cole et al. [8] and Bolormaa et al. [21], we found that none of our

Table 8 Genome-wide significant SNPs compared with the SNPs reported by Cole et al. [8]

\begin{tabular}{|c|c|c|c|c|c|}
\hline Chr. & Position (bp) ${ }^{a}$ & Trait $^{a}$ & Position (bp) & Distance (bp) & Trait $^{b}$ \\
\hline 12 & 53100776 & Dairy character & 52240216 & 860,560 & Teat length, Rear leg side view \\
\hline 16 & 21821449 & Dairy character & 21741980 & 79,469 & Somatic cell score \\
\hline 16 & 21821449 & Dairy character & 22179897 & 358,448 & Rear teat placement \\
\hline 16 & 21821449 & Dairy character & 22272329 & 450,880 & Somatic cell score, Rear teat placement \\
\hline 16 & 21821449 & Dairy character & 22406467 & 585,018 & Somatic cell score \\
\hline 18 & 4852600 & Capacity & 5655435 & 802,835 & Foot angle \\
\hline 5 & 110149999 & Conformation (final score) & 110886859 & 736,860 & Fore udder attachment, Rear udder height, Udder depth \\
\hline 5 & 110149999 & Conformation (final score) & 110910712 & 760,713 & Fore udder attachment, Udder depth \\
\hline 7 & 30964539 & Capacity & 31136178 & 171,639 & Somatic cell score \\
\hline 7 & 30964539 & Capacity & 31217950 & 253,411 & Somatic cell score \\
\hline 7 & 30964539 & Capacity & 31655835 & 691,296 & Teat length \\
\hline
\end{tabular}

${ }^{a}$ Results from our study; ${ }^{b}$ results reported by Cole et al. [8] Distance, the distance on the corresponding chromosome between the positions of the two SNPs (ours and the corresponding SNP from Cole et al.). 
significant SNPs were the same as the SNPs reported by Cole et al. [8] or Bolormaa et al. [21]. However, some of our SNPs were close to the significant SNPs reported by Cole et al. [8] that were associated with different traits (Table 8).

\section{Discussion}

In this study, we performed a GWAS for 29 conformation traits in a population of Chinese Holstein cows. A two-step strategy was applied to estimate SNP effect, and first we selected 500 SNPs using SMMA. We originally planned to select SNPs with $P$-values $<0.01\left(-\log _{10}\right.$ $(P)>2$ ), and we found that about 500 SNPs met this condition for the 29 traits (the $-\log _{10}(P)$ values at the 500th marker were sorted into descending order for the 29 traits and ranged from 2.089 to 2.421). Therefore, we decided to use the top 500 SNPs for the multiple QTL analysis. In other words, the selected 500 SNPs include nearly all the SNPs with $P$-values $<0.01$.

We found five SNPs located within previously reported QTL regions that were associated with conformationrelated traits. The SNP on BTA12 associated with angularity is $261 \mathrm{~kb}$ away from HTR2A and is located within a QTL region that has been reported by Schrooten et al. [22] to be associated with angularity. The SNP on BTA29 associated with stature is $81 \mathrm{~kb}$ away from LOC782090 and is within a large QTL region that has been found to significantly affect Angus body height at maturity [35]. The SNP on BTA24 associated with rear leg side view is near ZNF521 and is within a QTL region that has been reported to have a significant effect on dairy cattle rear leg set [22]. The SNP on BTA10 associated with teat length is near PDIA6 and is located within a QTL region that has been shown to have a significant effect on teat length [36]. And, the SNP on BTA25 associated with animal size is near TMEM130 and is within a QTL region that has been reported to affecting calf size in Danish Holstein cattle [37]. Besides, most of significant SNPs that we detected in this study are located within QTL regions that have been reported previously to affect production, longevity, and reproduction traits in dairy cattle $[21,35,36,38,39]$.

We also found several SNPs located within genes that are known to have functions related to the development and metabolism of animal tissues. The SNP (Hapmap40339-BTA-117016; Table 4) on BTA3 which was associated with both capacity and body depth is $7 \mathrm{~kb}$ away from the gene, Duffy blood group, chemokine receptor (DARC). Hai et al. [40] performed a bivariate GWAS in human to identify the SNPs associated with lean body mass and age at menarche and reported that $D A R C$ may play an important role in regulating the metabolisms of both these traits. The SNP (BTA-110160no-rs; Table 4) on BTA8 associated with chest width is
$121 \mathrm{~kb}$ away from the growth arrest specific 1 (GAS1) gene. GAS1 is highly expressed in quiescent mammalian cells and its over-expression in normal and some cancer cell lines was reported to inhibit G0/G1 transition [41]. It was found that GAS1 was expressed by chondrocytes after the cartilage started to differentiate [41]. The SNP on BTA4 associated with foot angle is $37 \mathrm{~kb}$ away from the myotrophin $(M T P N)$ gene, which plays an important role in cell and skeletal muscle growth [42]. These genes are suggested as functional candidate genes for body conformation traits.

Generally, different SNPs are associated with different traits, but some SNPs have been found to affect more than one trait. In our study, SNP Hapmap40339-BTA117016 (Table 4) was associated with both capacity and body depth, SNP ARS-BFGL-NGS-115067 (Table 4) was associated with both capacity and animal size, SNP ARSBFGL-NGS-14022 (Table 3) was associated with both dairy character and angularity, and SNP BTB-01238380 (Tables 3 and 4) was associated with both dairy character and height at front end. The genetic correlation between each of these pairs of genes was 0.51, 0.77, 0.86, and 0.35 , which suggested that these four SNPs likely contribute to genetic correlation and perhaps have a pleiotropic effect on each pair of traits.

\section{Conclusions}

The present genome-wide association study identified 59 significant SNPs associated with 26 conformation traits in a Chinese Holstein cattle population. Some of these SNPs were located within or near previously reported genes and QTL regions, while some of the SNPs were new discoveries. We found that DARC, GAS1, MTPN, HTR2A, ZNF521, PDIA6, and TMEM130 were the most promising candidate genes for capacity and body depth, chest width, foot angle, angularity, rear leg side view, teat length, and animal size traits, respectively.

\section{Additional files}

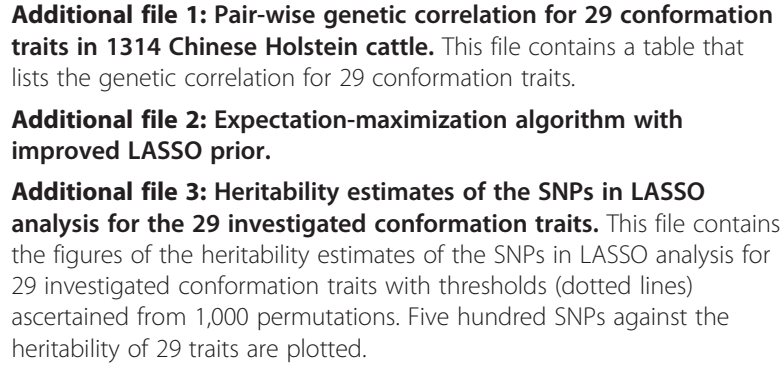

Additional file 1: Pair-wise genetic correlation for 29 conformation traits in 1314 Chinese Holstein cattle. This file contains a table that lists the genetic correlation for 29 conformation traits.

Additional file 2: Expectation-maximization algorithm with improved LASSO prior.

Additional file 3: Heritability estimates of the SNPs in LASSO analysis for the $\mathbf{2 9}$ investigated conformation traits. This file contains the figures of the heritability estimates of the SNPS in LASSO analysis for 29 investigated conformation traits with thresholds (dotted lines) ascertained from 1,000 permutations. Five hundred SNPs against the heritability of 29 traits are plotted.

\section{Abbreviations}

GWAS: Genome-wide association study; EBV: Estimate breeding value; SNP: Single-nucleotide polymorphism; QTL: Quantitative trait locus; BTA: Bos taurus automosome; LASSO: Least absolute shrinkage and selection operator; DAC: Dairy Association of China; DHI: Dairy Herd Improvement system; 
MAF: Minor allele frequency; SMMA: Single trait mixed model analysis; GAS1: Growth arrest specific 1; HTR2A: 5-hydroxytryptamine (serotonin) receptor 2A; ANKRD54: Ankyrin repeat domain 54; DHX35: DEAH (Asp-Glu-Ala-His) box polypeptide 35; DOCK10: Dedicator of cytokinesis 10; DRG1: Developmentally regulated GTP binding protein 1; DARC: Duffy blood group, chemokine receptor; LRP2: Low density lipoprotein receptor-related protein 2; MACROD2: MACRO domain containing 2; MTPN: Myotrophin; PDIA6: Protein disulfide isomerase family A, member 6; SCEL: Sciellin; SH3RF3: SH3 domain containing ring finger 3; SLC25A24: Solute carrier family 25 (mitochondrial carrier; phosphate carrier): Member 24; SLC39A11: Solute carrier family 39 (metal ion transporter), member 11; SPATA17: Spermatogenesis associated 17; TMEM130: Transmembrane protein 130; ZNF521: Zinc finger protein 52.

\section{Competing interests}

The authors declare that they have no competing interests.

\section{Authors' contributions}

XW performed the genome-wide association analysis and prepared the manuscript. MF contributed to the statistical and results analysis, and contributed to manuscript writing. SW contributed to genotype imputation on $\mathrm{V} 1$ and $\mathrm{V} 250 \mathrm{~K}$ chips. $J \mathrm{~L}$ and XD participated in the data analysis. SZ participated in the data analysis and experiment design, $L L$ and $L Q$ performed the conformation trait measurements and EBV estimation. QZ and $Y Z$ participated in the experiment design and result interpretation. LM and GS revised the manuscript and participated in interpreting the result. DS conceived and designed the experiments and prepared the manuscript. All authors read and approved the final manuscript.

\section{Acknowledgments}

This work was supported by the National Science and Technology Program of China (2013AA102504, 2011BAD28B02, 2012BAD12B01), the Beijing Innovation Team of Technology System in the National Dairy Industry, 948 Program (2011-G2A), the Beijing Research and Technology program (D121100003312001), the Program for Changjiang Scholar and Innovation Research Team in University (IRT1191), the National Natural Science Foundation of China (Grant No. 31001001), and the Program for New Century Excellent Talents In Heilongjiang Provincial University (Grant No. 1253-NCET-001).

\section{Author details}

"Key Laboratory of Animal Genetics and Breeding of Ministry of Agriculture, National Engineering Laboratory for Animal Breeding, College of Animal Science and Technology, China Agricultural University, 2 Yuanmingyuan West Road, Beijing 100193, China. ${ }^{2}$ Beijing Dairy Cattle Center, Beijing 100192, China. 'Life Science College, Heilongjiang Bayi Agricultural University, Daqing 163319, China. ${ }^{4}$ Center for Quantitative Genetics and Genomics, Department of Molecular Biology and Genetics, Aarhus University, DK-8830 Tjele, Denmark.

Received: 12 March 2013 Accepted: 10 December 2013 Published: 17 December 2013

\section{References}

1. Vollema AR, Van der Beek S, Harbers AGF, De Jong G: Genetic evaluation for longevity of dutch dairy bulls. J Dairy Sci 2000, 83(11):2629-2639.

2. Lund T, Miglior F, Dekkers JCM, Burnside EB: Genetic-relationships between clinical mastitis, somatic-cell count, and udder conformation in Danish Holsteins. Livest Prod Sci 1994, 39(3):243-251.

3. Short TH, Lawlor TJ: Genetic-parameters of conformation traits, milk-yield, and herd life in Holsteins. J Dairy Sci 1992, 75(7):1987-1998.

4. Pozveh ST, Shadparvar AA, Shahrbabak MM, Taromsari MD: Genetic analysis of reproduction traits and their relationship with conformation traits in Holstein cows. Livest Sci 2009, 125(1):84-87.

5. Klein RJ, Zeiss C, Chew EY, Tsai JY, Sackler RS, Haynes C, Henning AK SanGiovanni JP, Mane SM, Mayne ST, et al: Complement factor $\mathrm{H}$ polymorphism in age-related macular degeneration. Science 2005, 308(5720):385-389.

6. Johnson $\mathrm{AD}$, O'Donnell $\mathrm{CJ}$ : An open access database of genome-wide association results. Bmc Med Genet 2009, 10:6.
7. Flint J, Eskin E: Genome-wide association studies in mice. Nat Rev Genet 2012, 13(11):807-817.

8. Cole JB, Wiggans GR, Ma L, Sonstegard TS, Lawlor TJ Jr, Crooker BA, Van Tassell CP, Yang J, Wang S, Matukumalli LK, et al: Genome-wide association analysis of thirty one production, health, reproduction and body conformation traits in contemporary U.S. Holstein cows. BMC Genomics 2011, 12:408.

9. Zanella R, Settles ML, McKay SD, Schnabel R, Taylor J, Whitlock RH, Schukken Y, Van Kessel JS, Smith JM, Neibergs HL: Identification of loci associated with tolerance to Johne's disease in Holstein cattle. Anim Genet 2011, 42(1):28-38

10. Jiang L, Liu JF, Sun DX, Ma PP, Ding XD, Yu Y, Zhang Q: Genome wide association studies for milk production traits in Chinese Holstein population. Plos One 2010, 5(10):e13661.

11. Daetwyler HD, Schenkel FS, Sargolzaei M, Robinson JA: A genome scan to detect quantitative trait loci for economically important traits in Holstein cattle using two methods and a dense single nucleotide polymorphism map. J Dairy Sci 2008, 91(8):3225-3236.

12. Schennink A, Stoop WM, Visker MH, van der Poel JJ, Bovenhuis $H$, van Arendonk JA: Short communication: genome-wide scan for bovine milk-fat composition. II. Quantitative trait loci for long-chain fatty acids. J Dairy Sci 2009, 92(9):4676-4682.

13. Kolbehdari D, Wang Z, Grant JR, Murdoch B, Prasad A, Xiu Z, Marques E, Stothard P, Moore SS: A whole genome scan to map QTL for milk production traits and somatic cell score in Canadian Holstein bulls. J Anim Breed Genet 2009, 126(3):216-227.

14. Olsen HG, Hayes BJ, Kent MP, Nome T, Svendsen M, Larsgard AG, Lien S: Genome-wide association mapping in Norwegian Red cattle identifies quantitative trait loci for fertility and milk production on BTA12. Anim Genet 2011, 42(5):466-474

15. Bouwman AC, Bovenhuis H, Visker MHPW, van Arendonk JAM: Genomewide association of milk fatty acids in Dutch dairy cattle. Bmc Genet 2011, 12:43

16. Sahana G, Guldbrandtsen B, Lund MS: Genome-wide association study for calving traits in Danish and Swedish Holstein cattle. J Dairy Sci 2011, 94(1):479-486

17. Kim ES, Berger PJ, Kirkpatrick BW: Genome-wide scan for bovine twinning rate QTL using linkage disequilibrium. Anim Genet 2009, 40(3):300-307.

18. Feugang JM, Kaya A, Page GP, Chen L, Mehta T, Hirani K, Nazareth L, Topper E, Gibbs R, Memili E: Two-stage genome-wide association study identifies integrin beta 5 as having potential role in bull fertility. BMC Genomics 2009, 10:176.

19. Pant SD, Schenkel FS, Verschoor CP, You QM, Kelton DF, Moore SS, Karrow NA: A principal component regression based genome wide analysis approach reveals the presence of a novel QTL on BTA7 for MAP resistance in holstein cattle. Genomics 2010, 95(3):176-182.

20. Kirkpatrick BW, Shi X, Shook GE, Collins MT: Whole-genome association analysis of susceptibility to paratuberculosis in Holstein cattle. Anim Genet 2011, 42(2):149-160.

21. Bolormaa S, Hayes BJ, Savin K, Hawken R, Barendse W, Arthur PF, Herd RM, Goddard ME: Genome-wide association studies for feedlot and growth traits in cattle. J Anim Sci 2011, 89(6):1684-1697.

22. Schrooten C, Bovenhuis $\mathrm{H}$, Coppieters W, Van Arendonk JAM: Whole genome scan to detect quantitative trait loci for conformation and functional traits in dairy cattle. J Dairy Sci 2000, 83(4):795-806.

23. Ashwell MS, Heyen DW, Weller II, Ron M, Sonstegard TS, Van Tassell CP, Lewin HA: Detection of quantitative trait loci influencing conformation traits and calving ease in Holstein-Friesian cattle. J Dairy Sci 2005, 88(11):4111-4119.

24. Schrooten C, Bink MCAM, Bovenhuis H: Whole genome scan to detect chromosomal regions affecting multiple traits in dairy cattle. J Dairy SCi 2004, 87(10):3550-3560.

25. Dairy Data Center of China. [http://www.holstein.org.cn/newsDetail.jsp? lanm $=04 \&$ wenzid $=28$ ]

26. Beijing Dairy Cattle Center. [http://www.bdcc.com.cn/]

27. Weijia G: Study on Population Genetic Analysis of Chinese Holstein (Chinese). China: China Agriculture University; 2010.

28. Canadian Dairy Network. [http://www.cdn.ca]

29. Browning BL, Browning SR: A unified approach to genotype imputation and haplotype-phase inference for large data sets of trios and unrelated individuals. Am J Hum Genet 2009, 84(2):210-223. 
30. Browning BL, Browning SR: Rapid and accurate haplotype phasing and missing data inference for whole genome association studies using localized haplotype clustering. Genet Epidemiol 2007, 31(6):606-606.

31. Tibshirani R: Regression shrinkage and selection via the Lasso. J Roy Stat Soc B Met 1996, 58(1):267-288.

32. Fang $M$, Jiang $D$, Li DD, Yang $R Q$, Fu WX, Pu LJ, Gao HJ, Wang GH, Yu LY: Improved LASSO priors for shrinkage quantitative trait loci mapping. Theor Appl Genet 2012, 124(7):1315-1324.

33. National Animal Genome Research Program. [http://www.animalgenome.org/]

34. National Center for Biotechnology Information. [http://www.ncbi.nlm.nih. gov/]

35. McClure MC, Morsci NS, Schnabel RD, Kim JW, Yao P, Rolf MM, McKay SD, Gregg SJ, Chapple RH, Northcutt SL, et al: A genome scan for quantitative trait loci influencing carcass, post-natal growth and reproductive traits in commercial Angus cattle. Anim Genet 2010, 41(6):597-607.

36. Schnabel RD, Sonstegard TS, Taylor JF, Ashwell MS: Whole-genome scan to detect QTL for milk production, conformation, fertility and functional traits in two US Holstein families. Anim Genet 2005, 36(5):408-416.

37. Thomasen JR, Guldbrandtsen B, Sorensen P, Thomsen B, Lund MS:

Quantitative trait loci affecting calving traits in Danish Holstein cattle. J Dairy Sci 2008, 91(5):2098-2105.

38. Boichard D, Grohs C, Bourgeois F, Cerqueira F, Faugeras R, Neau A, Rupp R, Amigues $\mathrm{Y}$, Boscher MY, Leveziel $\mathrm{H}$ : Detection of genes influencing economic traits in three French dairy cattle breeds. Genet Sel Evol 2003, 35(1):77-101.

39. Seidenspinner T, Bennewitz J, Reinhardt F, Thaller G: Need for sharp phenotypes in QTL detection for calving traits in dairy cattle. J Anim Breed Genet 2009, 126(6):455-462

40. Hai R, Zhang L, Pei YF, Zhao LJ, Ran S, Han YY, Zhu XZ, Shen H, Tian Q, Deng HW: Bivariate genome-wide association study suggests that the DARC gene influences lean body mass and age at menarche. Sci China Life Sci 2012, 55(6):516-520.

41. Lee KK, Leung AK, Tang MK, Cai DQ, Schneider C, Brancolini C, Chow PH: Functions of the growth arrest specific 1 gene in the development of the mouse embryo. Dev Biol 2001, 234(1):188-203.

42. Wang $L$, Wang $Y$ : Molecular characterization, expression patterns and subcellular localization of Myotrophin (MTPN) gene in porcine skeletal muscle. Mol Biol Rep 2012, 39(3):2733-2738.

doi:10.1186/1471-2164-14-897

Cite this article as: Wu et al:: Genome wide association studies for body conformation traits in the Chinese Holstein cattle population. BMC Genomics 2013 14:897.

\section{Submit your next manuscript to BioMed Central and take full advantage of:}

- Convenient online submission

- Thorough peer review

- No space constraints or color figure charges

- Immediate publication on acceptance

- Inclusion in PubMed, CAS, Scopus and Google Scholar

- Research which is freely available for redistribution 